\title{
Conversion and pharmacokinetics profiles of a novel pro-drug of 3-n-butylphthalide, potassium 2-(1-hydroxypentyl)-benzoate, in rats and dogs
}

\author{
Jiang LI, Shao-feng XU, Ying PENG, Nan FENG, Ling WANG, Xiao-liang WANG* \\ State Key Laboratory of Bioactive Substances and Functions of Natural Medicines, Institute of Materia Medica, Chinese Academy of \\ Medical Sciences \& Peking Union Medical College, Beijing 100050, China
}

\begin{abstract}
Potassium 2-(1-hydroxypentyl)-benzoate ( $d$ l-PHPB) is a novel pro-drug of 3-n-butylphthalide ( $d$ l-NBP) that is used to treat ischemic stroke. Currently, dl-PHPB is in phase II-III clinical trials in China. In this study, we investigated the conversion and pharmacokinetics profiles of dl-PHPB in vitro and in vivo. The conversion of $\mathrm{dl}$-PHPB to $\mathrm{dl}$-NBP was $\mathrm{pH}$ - and calcium-dependent, and paraoxonase was identified as a major enzyme for the conversion in rat plasma. The pharmacokinetics, tissue distribution and excretion of $d l-P H P B$ were studied and compared with equal-molar doses of $d I$-NBP in rats and dogs. The in vivo studies showed that dl-PHPB could be quickly and completely converted to $\mathrm{dl}$-NBP. The plasma concentration-time course of converted dl-NBP after intravenous $d /$-PHPB administration was nearly the same as that after equal-molar dl-NBP. The $C_{\max }$ and AUC of dl-NBP after oral dl-PHPB administration in rats and dogs were higher by $60 \%$ and $170 \%$, respectively, than those after oral $d$-NBP administration. Analysis of the tissue distribution of $d l$-PHPB revealed that converted $d I$-NBP was primarily distributed in fat, the brain and the stomach. In the brain, the levels of $d l-N B P$ were relatively higher after $d I$-PHPB treatment by orally than after treatment with equal-molar $d I$-NBP. Approximately 3\%-4\% of $d I$-NBP was excreted within $72 \mathrm{~h}$ after dosing with dl-PHPB or dl-NBP, but no dl-PHPB was detected in urine or feces excrements. Our results demonstrate that the conversion of $d l$-PHPB is fast after oral or intravenous administration. Furthermore, the bioavailability of $d l-P H P B$ was obviously better than that of $d l-N B P$.
\end{abstract}

Keywords: potassium 2-(1-hydroxypentyl)-benzoate (dl-PHPB); pro-drug; 3-n-butylphthalide (dl-NBP); ischemic stroke; pharmacokinetics; bioavailability

Acta Pharmacologica Sinica (2018) 39: 275-285; doi: 10.1038/aps.2017.90; published online 14 Sep 2017

\section{Introduction}

Potassium 2-(1-hydroxypentyl)-benzoate (dl-PHPB), a potential pro-drug of $3-n$-butylphthalide $(d l$-NBP) with a novel molecular structure, has been developed as an anti-cerebral ischemia agent with extremely high solubility in water ${ }^{[1]}$. The phase I clinical trial of $d l$-PHPB has been completed, and $d l$ PHPB is now in phase II-III clinical studies.

$\mathrm{Dl}$-NBP is an oily compound with a boiling point of $140-141$ ${ }^{\circ} \mathrm{C}(320 \mathrm{~Pa})$ that was originally isolated from the seeds of Apium graveolens Linn, or Chinese celery ${ }^{[2]}$. It has been widely used for ischemic stroke and has shown good therapeutic effects in China ${ }^{[3-7]}$. However, $d l-N B P$ is hydrophobic and is difficult to be intravenously administered, which limits the use of $d l$-NBP in patients with cerebral ischemic stroke ${ }^{[7]}$. Additionally, the

\footnotetext{
* To whom correspondence should be addressed.

E-mail wangx।@imm.ac.cn

Received 2017-02-15 Accepted 2017-06-05
}

bioavailability of $d l$-NBP is very low ${ }^{[7]}$. $D l$-PHPB has been designed and synthesized by the Department of Medicinal Chemistry, Institute of Materia Medica, Chinese Academy of Medical Sciences as a pro-drug of $d l$-NBP with very good solubility in water. Dl-PHPB can be converted to an active metabolite ( $d l$-NBP) under certain chemical (ie, acidic) and biological conditions. Pharmacological studies have demonstrated that $d l$-PHPB exhibited similar or stronger neuroprotective effects than $d l-\mathrm{NBP}$ at equal-molar doses ${ }^{[1,8-10]}$. The mechanisms underlying the anti-stroke properties of $d l$-PHPB include increased regional cerebral blood flow in ischemic zones and inhibited platelet aggregation ${ }^{[1,8,9]}$. Recent studies have shown that $d l$-PHPB improved cognitive defects by attenuating amyloid and tau protein pathologies in APP/ PS1 transgenic mice, promoting long-term potentiation (LTP) in $\mathrm{A} \beta_{1-42}$-injected rats and APP/PS1 mice $\mathrm{e}^{[10-12]}$. Additionally, dl-PHPB protected neurons against $\mathrm{H}_{2} \mathrm{O}_{2}$-induced apoptosis in human neuroblastoma SK-N-SH cells by modulating 
apoptosis-related proteins; the PKC signaling pathway may also be involved in these mechanisms ${ }^{[13]}$.

Although the pharmacological properties of $d l$-PHPB have been intensively investigated, its conversion, absorption, distribution, metabolism and excretion have not been well understood. Only a few studies have investigated the conversion of $d l-\mathrm{PHPB}$ in rat plasma ${ }^{[1]}$. Thus, the elucidation of the conversion and metabolism of $d l$-PHPB for clinical pharmacology and safety evaluations is very important.

In this study, we assessed in vitro studies to reveal the conversion mechanisms of $d l$-PHPB to $d l$-NBP and considered non-enzymatic acidic and alkaline solutions, calcium-dependent effect and plasma enzyme-mediated conversions. We also carried out in vivo studies to compare the pharmacokinetics, distribution and excretion of $d l-\mathrm{PHPB}$ with its metabolite $d l$-NBP after oral and intravenous administration in SD rats and Beagle dogs.

\section{Materials and methods}

\section{Animals}

SD rats (male and female, 190-210 g) were purchased from Vital River Lab Animal Technology Co, Ltd (Beijing, China), and Beagle dogs were obtained from Marshall Biotechnology Co, Ltd (Beijing, China). Animals were allowed free access to food and water in a temperature-controlled environment at $22^{\circ} \mathrm{C}-25^{\circ} \mathrm{C}$ during the experimental period. The experiments were performed in accordance with the guidelines for the care and use of laboratory animals and were approved by the Animal Care Committee of the Peking Union Medical College and the Chinese Academy of Medical Sciences (Beijing, China).

\section{Chemicals and materials}

$D l$-PHPB and $d l$-NBP were offered by the Department of Synthetic Pharmaceutical Chemistry of the Institute of Materia Medica (Beijing, China) with purities of $99.1 \%$, and $99.0 \%$, respectively. The chemical structures of the two compounds are shown in Figure 1. Internal standards of 4-biphenylacetic acid and diazepam were purchased from the National Institute for the Control of Pharmaceutical and Biological Products (NICPBP, Beijing, China). Sodium bis-p-nitrophenyl phosphate (BNPP), 5,5'-dithiobis-2-nitrobenzoic acid (DTNB), phenylmethylsulfonyl fluoride (PMSF), teicoplanin, donepezil, ethylenediamine tetraacetic acid disodium salt dehydrate (EDTA- $\mathrm{Na}_{2}$ ), ethyleneglycol-bis (2-aminoethylether)-tetraacetic acid (EGTA), and sodium fluoride (NaF) were purchased from Sigma-Aldrich (St Louis, MO, USA). High-performance liq-

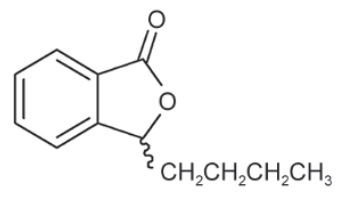

dl-NBP

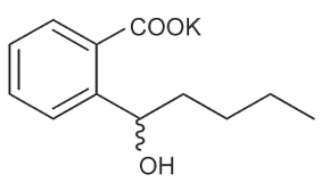

dl-PHPB uid chromatography (HPLC) grade methanol was purchased from Burdick \& Jackson Company (Muskegon, MI, USA). All other reagents were of analytical grade. Deionized water used throughout the study was purified using a Millipore water purification system (Milford, MA, USA).

Fresh whole blood was collected and pooled from healthy SD rats and beagle dogs with heparin or EDTA- $\mathrm{Na}_{2}$ as an anticoagulant. Plasma was separated by centrifugation at $1123 \times g$ at $4^{\circ} \mathrm{C}$ for $10 \mathrm{~min}$. All pooled plasma was stored at $-70^{\circ} \mathrm{C}$ and thawed at $4^{\circ} \mathrm{C}$ before assays.

\section{Conversion of $d l-P H P B$ in solutions of different $\mathrm{pH}$ values}

Appropriate amounts of deionized water, $1.0 \mathrm{~mol} / \mathrm{L} \mathrm{HCl}$, and $1.0 \mathrm{~mol} / \mathrm{L} \mathrm{NaOH}$ were used to make solutions with 1.0, 3.0, 7.0 , and $9.0 \mathrm{pH}$. Reactions were initiated by adding an aliquot of a stock solution of $d l$-PHPB $(1 \mathrm{mg} / \mathrm{mL}$, in methanol) to obtain a final concentration of $10 \mu \mathrm{g} / \mathrm{mL}$. The samples were allowed to settle for various time intervals from 0 to $360 \mathrm{~min}$ at $37^{\circ} \mathrm{C}$. An internal standard at a final concentration of 5 $\mu \mathrm{g} / \mathrm{mL}$ was added to each sample, and the samples were analyzed without any pre-treatment by HPLC as described below. A control sample of $d l$-PHPB $(10 \mu \mathrm{g} / \mathrm{mL}$ in methanol) or $d l-$ NBP $(7.8 \mu \mathrm{g} / \mathrm{mL}$ in methanol) was prepared and analyzed. For each sample, three replicated operations were performed. Residual percentage versus $\mathrm{pH}$ value was plotted, and degradation trends were observed.

Residual $\%$ of $d l$-PHPB or $d l$-NBP was calculated as follows:

$$
\text { Residual } \%=\text { A } / \text { B (control) } \times 100 \%
$$

where A represents the concentration of $d l$-PHPB or $d l$-NBP produced by the solutions with different $\mathrm{pH}$ values and various time intervals, and $\mathrm{B}$ represents the control concentration of $d l$-PHPB or $d l$-NBP.

\section{Conversion of $d l$-PHPB in SD rat plasma}

SD rat plasma with heparin as an anticoagulant was pre-incubated at $37^{\circ} \mathrm{C}$ for $5 \mathrm{~min}$. The reaction was initiated by adding dl-PHPB solution $(1 \mathrm{mg} / \mathrm{mL}$, in methanol) to achieve a final concentration of $10 \mu \mathrm{g} / \mathrm{mL}$. The temperature was maintained at $37^{\circ} \mathrm{C}$, representing body temperature, for the treatment of the plasma samples. A control sample of $d l$-PHPB $(10 \mu \mathrm{g} / \mathrm{mL}$ in methanol) or of $d l-\mathrm{NBP}(7.8 \mu \mathrm{g} / \mathrm{mL}$ in methanol) was prepared. At different time intervals (0 to $360 \mathrm{~min}$ ) at $37^{\circ} \mathrm{C}$, a sample of $200 \mu \mathrm{L}$ was withdrawn. The reaction was stopped by adding $50 \mu \mathrm{L}$ of saturated EDTA- $\mathrm{Na}_{2}$ solution $(0.3 \mathrm{~mol} / \mathrm{L})$ and by placing the samples on ice. For each sample, three replicated operations were performed. Residual percentage versus time was plotted. The quantifications of $d l$-PHPB and its active metabolite ( $d l-\mathrm{NBP})$ in these samples were performed by HPLC methods as described below.

Residual \% of $d l$-PHPB or $d l$-NBP was calculated as follows:

Residual $\%=$ A/B (control) $\times 100 \%$

Figure 1. Structures of $d l-\mathrm{NBP}$ and $d l-\mathrm{PHPB}$. 
produced by the incubation in rat plasma with different time intervals, and $\mathrm{B}$ represents the control concentration of $d l$ PHPB or $d l$-NBP.

\section{Effects of esterase inhibitors on dI-PHPB conversion}

To characterize the esterases responsible for $d l$-PHPB conversion, $d l$-PHPB was incubated in rat plasma with heparin as an anticoagulant in the presence of various esterase inhibitors. This assay was conducted according to described methods, with modifications ${ }^{[14-17]}$. Briefly, the rat plasma $(100 \mu \mathrm{L})$ was mixed with $350 \mu \mathrm{L}$ of $50 \mathrm{mmol} / \mathrm{L}$ Tris- $\mathrm{HCl}$ buffer (pH 7.4) and either $50 \mu \mathrm{L}$ of the inhibitor solution (in 10\% $v / v$ DMSO in water) or $50 \mu \mathrm{L}$ of $10 \%$ DMSO (as control). The reaction was initiated by adding $20 \mu \mathrm{L}$ of $d l$-PHPB solution $(300 \mu \mathrm{g} / \mathrm{mL}$, in methanol). The mixtures were incubated at $37^{\circ} \mathrm{C}$ for $2 \mathrm{~h}$. The reaction was stopped using $80 \mu \mathrm{L}$ of saturated EDTA- $\mathrm{Na}_{2}$ solution, and the tubes were placed on ice.

The quantification of $d l$-PHPB and $d l-\mathrm{NBP}$ in these samples was performed by HPLC methods as described below. The conversion of $d l$-PHPB was calculated as follows:

Conversion of $d l-\mathrm{PHPB} \%=\mathrm{A} / \mathrm{B}$ (control) $\times 100 \%$

where A and B (control) represent the $d l$-NBP amounts produced by the incubation with and without the inhibitor, respectively.

\section{Conversion of $d I-\mathrm{PHPB}$ in SD rats}

The vivo conversion of $d l$-PHPB was studied in SD rats with intravenous injections of $20 \mathrm{mg} / \mathrm{kg} d l$-PHPB. The plasma concentration time curves of $d l$-PHPB and its metabolite $d l$-NBP were measured by HPLC methods.

Briefly, $300 \mu \mathrm{L}$ blood samples from the femoral vein were collected into tubes containing $10 \mu \mathrm{L}$ of saturated EDTA- $\mathrm{Na}_{2}$ at different time intervals after dosing. The blood samples were immediately centrifuged at $1123 \times \mathrm{g}$ for $5 \mathrm{~min}$, and the plasma was stored at $-70^{\circ} \mathrm{C}$ until HPLC analysis.

\section{Plasma pharmacokinetics}

Comparative studies on plasma pharmacokinetics of $d l$ PHPB and $d l$-NBP were carried out in Beagle dogs and SD rats. According to previous reports ${ }^{[1]}$, the effective doses of $d l$-PHPB in rats subjected to acute focal cerebral ischemiareperfusion were $5-10 \mathrm{mg} / \mathrm{kg}$ and $50-100 \mathrm{mg} / \mathrm{kg}$ by intravenous or oral administration, respectively. Thus, the following dosage ranges were selected to cover the effective dose of $d l-$ PHPB. The concentration time curves of $d l-\mathrm{PHPB}$ and its active metabolite (dl-NBP) were measured after treatment with $d l$-PHPB intravenously $(5,10$, and $20 \mathrm{mg} / \mathrm{kg}$ in SD rats or 2,4 , and $8 \mathrm{mg} / \mathrm{kg}$ in Beagle dogs) and orally (50, 100, and 200 $\mathrm{mg} / \mathrm{kg}$ in SD rats or 10, 30, and $100 \mathrm{mg} / \mathrm{kg}$ in Beagle dogs). According to the molecular weights of the two compounds, $d l$-NBP was given at $15.6 \mathrm{mg} / \mathrm{kg}$ in SD rats and $6.2 \mathrm{mg} / \mathrm{kg}$ in Beagle dogs intravenously and at $156.0 \mathrm{mg} / \mathrm{kg}$ in SD rats and $23.4 \mathrm{mg} / \mathrm{kg}$ in Beagle dogs orally. Then, $300 \mu \mathrm{L}$ blood samples were collected at different time intervals after dosing, accord- ing to the procedure described above. The plasma was stored at $-70^{\circ} \mathrm{C}$ until HPLC analysis.

\section{Tissue distribution and excretion}

$\mathrm{SD}$ rats were given $d \mathrm{l}-\mathrm{PHPB}(10 \mathrm{mg} / \mathrm{kg}$ intravenously or 100 $\mathrm{mg} / \mathrm{kg}$ orally) or equimolar doses of $d \mathrm{l}-\mathrm{NBP}(7.8 \mathrm{mg} / \mathrm{kg}$ intravenously or $78 \mathrm{mg} / \mathrm{kg}$ orally). Tissues from the heart, liver, spleen, lung, kidney, stomach, small intestine, fat, and brain were obtained at 20,60, 120, and 240 min by oral administration and at 20, 60, and 240 min by intravenous administration, respectively. Urine and feces samples were collected pre-dose and at $0-4,4-8,8-12,12-24$, and $24-36 \mathrm{~h}$ or at $24-48,36-48$, and $48-72 \mathrm{~h}$ post-dose. The total urine volume and total feces weight were recorded after each sample collection. The tissue, urine and feces samples were stored at $-70^{\circ} \mathrm{C}$ until analysis.

\section{Quantitative analysis of dl-PHPB and dl-NBP}

Preparation of plasma and urine samples For every $100 \mu \mathrm{L}$ aliquot of pooled plasma (or urine) samples, $300 \mu \mathrm{L}$ of methanol containing $10 \mu \mathrm{g} / \mathrm{mL}$ of internal standard were added. Mixtures were mixed for $1 \mathrm{~min}$ and centrifuged for $10 \mathrm{~min}$ at $12000 \times \mathrm{g}$. A $200 \mu \mathrm{L}$ aliquot of the supernatant was taken and filtered through a $0.22-\mu \mathrm{m}$ membrane. A $60 \mu \mathrm{L}$ aliquot was used for HPLC analysis.

Preparation of tissues and feces samples Each feces sample was thawed and placed in 5 parts $(1 \mathrm{~g}$ : $5 \mathrm{~mL})$ methanol. The mixture was homogenized by a motor-driven homogenizer (Fisher Scientific, Pittsburgh, PA, USA) and subjected to ultrasound treatment for $15 \mathrm{~min}$. A $5 \mathrm{~mL}$ aliquot of the mixture was removed and centrifuged at $3500 \times \mathrm{g}$ for $10 \mathrm{~min}$. A $400 \mu \mathrm{L}$ aliquot of the supernatant was taken and filtered through a $0.22-\mu \mathrm{m}$ membrane. A $60 \mu \mathrm{L}$ aliquot was used for HPLC analysis.

\section{HPLC analysis}

The concentrations of $d l$-PHPB and $d l-\mathrm{NBP}$ in plasma were determined by previously described HPLC methods ${ }^{[18-20]}$. An Agilent 1100 (Palo Alto, CA, USA) instrument was used. Standard curves with concentrations ranging from 0.05 to 60 $\mu \mathrm{g} / \mathrm{mL} d l-P H P B$ and 0.01 to $60 \mu \mathrm{g} / \mathrm{mL} d l-N B P$ in plasma and urine exhibited good linearity with correlation coefficients $>0.998$. The limits of the $d l$-PHPB and $d l$-NBP assays were $0.05 \mu \mathrm{g} / \mathrm{mL}$ and $0.01 \mu \mathrm{g} / \mathrm{mL}$, respectively, with acceptable precision and accuracy. The assay precision (deviation) was $<15 \%$, whereas the assay accuracy was $85 \%-115 \%$. The mean absolute percentage recoveries of $d l$-PHPB and $d l$-NBP were more than $70 \%$ from spiked plasma, urine, tissues, and feces samples determined at different concentrations of quality control (QC) samples. QC samples with three concentration levels were prepared in control stabilized samples at final concentrations of $0.5,10$, and $50 \mu \mathrm{g} / \mathrm{mL}$ for $d l-P H P B$ and $0.1,10$, and 50 $\mu \mathrm{g} / \mathrm{mL}$ for $\mathrm{dl}$-NBP. Intra- and inter-day plasma assay variability were less than $10 \%$. HPLC methods for the determinations of $d l$-PHPB or $d l$-NBP were reliable and reproducible because the $\% \mathrm{CV}$ and \% bias were below $15 \%$ for all theoretical con- 
centrations of $d l-\mathrm{PHPB}$ and $d l-\mathrm{NBP}$.

\section{Data analysis}

First order rate constants $(K)$ of conversion were calculated from the slopes of linear plots of residue percentage against time, and the corresponding half-life was obtained from the equation: $t_{1 / 2}=0.693 / K$. All values were obtained from three independent determinations, and the mean values of the constants were calculated. The pharmacokinetic parameters were analyzed using 3P97 computer software package (Chinese Pharmacology Society, Beijing, China). The statistical analysis of outcome parameters was performed using SPSS version 13.5 (SPSS Inc, Chicago, IL, USA). The statistical evaluation was performed using analysis of variance (ANOVA) followed by multiple comparison tests by Duncan's method. The level of significance was set at $P<0.05$.

\section{Results}

\section{Conversion of dl-PHPB to dl-NBP in vitro and in vivo}

The in vitro and in vivo conversions of $d l$-PHPB to $d l$-NBP are shown in Figure 2. To study the in vitro conversion, dl-PHPB was added to distilled water of different $\mathrm{pH}$ values (1.0, 3.0, 7.0 , and 9.0) or rat plasma and incubated at $37^{\circ} \mathrm{C}$ for different periods. The in vitro conversion of $d l$-PHPB into $d l-N B P$ showed a significant $\mathrm{pH}$ dependency. The level of $d l-\mathrm{PHPB}$

A

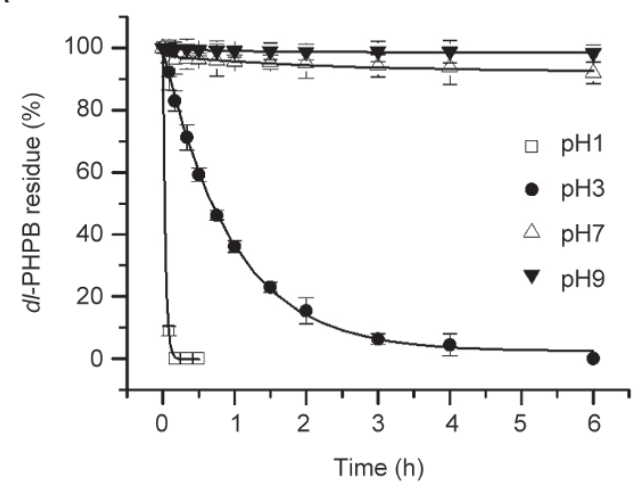

C

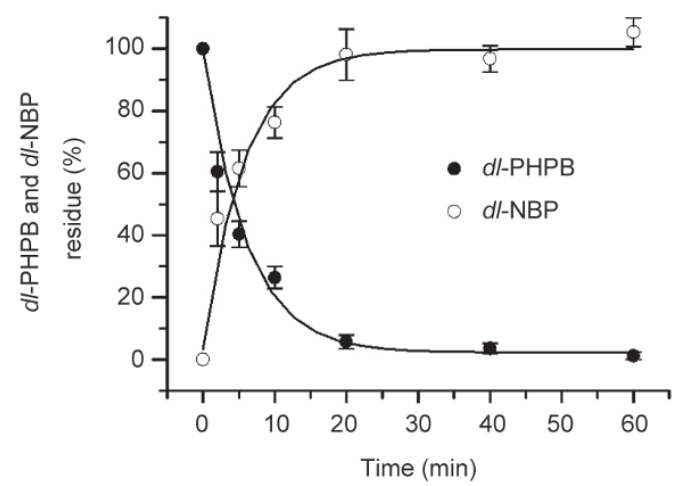

decreased rapidly and was undetectable at $\mathrm{pH} 1.0$ after $30 \mathrm{~min}$ of incubation, whereas the level of $d l$-NBP increased. However, $d l$-PHPB was stable in neutral and alkaline solutions. The residue concentrations of $d l$-PHPB were $93 \%$ and $96 \%$ at initial pH levels of 7.0 and 9.0 after 4 h of incubation, respectively. At the same time, lower levels of $d l$-NBP (approximately $7 \%$ and $5 \%$ of the maximum) were detected in the solutions (Figures 2A, 2B). The conversion rates agreed with the first order kinetics shown in Table 1. The conversion in rat plasma was even more rapid. After $20 \mathrm{~min}$ of incubation in rat plasma at $37^{\circ} \mathrm{C}$, more than $90 \%$ of $d l$-PHPB was converted into dl-NBP (Figure 2C).

The in vivo conversion studies were carried out in SD rats. Dl-PHPB was intravenously injected at $20 \mathrm{mg} / \mathrm{kg}$ body weight. The mean plasma concentration time curves of $d l$-PHPB and its active metabolite are shown in Figure 2D. After injecting $d l$-PHPB, the conversion of $d l$-PHPB to $d l$-NBP was very rapid in the rats and could not be detected after $30 \mathrm{~min}$; $d l$-NBP appeared at high levels immediately after injection. The concentrations of the active metabolite $d l$-NBP were at least 3 -fold higher than those of $d l$-PHPB at the same time points. The pharmacokinetic parameters of the active metabolite $d l$-NBP are listed in Table 2. A two-compartment open model provided the best fit to the plasma concentration time profiles of $d l$-NBP obtained in rats after intravenous treatment with
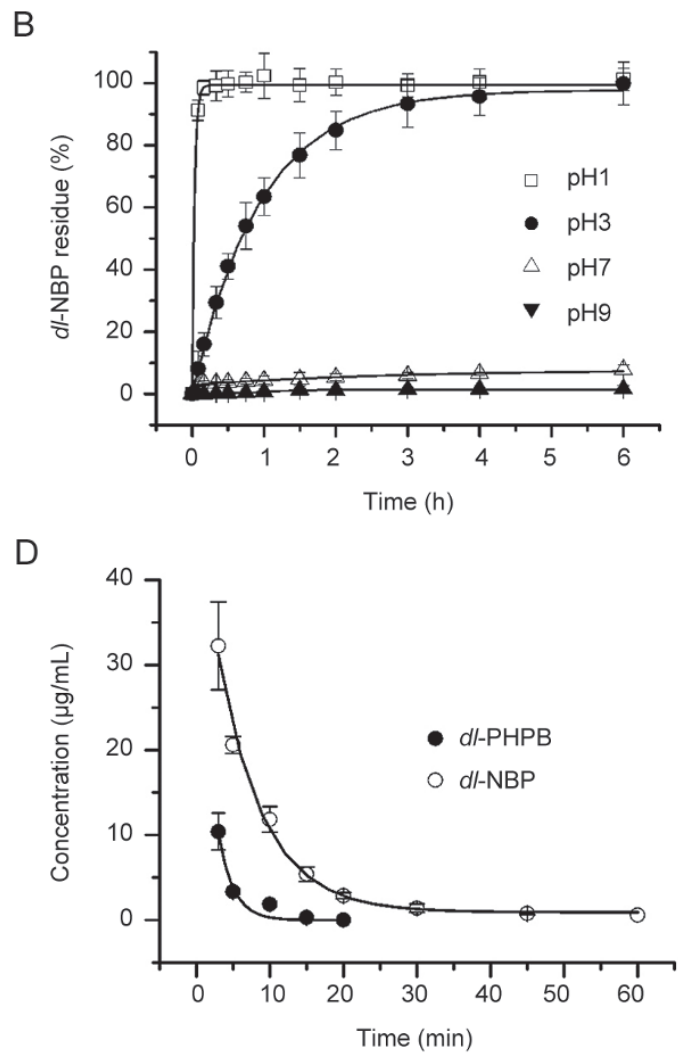

Figure 2. Time profile of $d l$-PHPB conversion. Time profiles of $d l$-PHPB and $d l$-NBP concentration in different pH solutions (A: $d l-\mathrm{PHPB}, \mathrm{B}$ : $d l$-NBP) and SD rat plasma (C) were obtained after incubation at a final concentration of $10 \mu \mathrm{g} / \mathrm{mL}$ for different times at $37^{\circ} \mathrm{C}$ (each point represents the mean \pm standard error of triplicate determinations). In vivo conversion (D), the mean plasma concentration versus time profiles of $d l$-PHPB and $d l$-NBP were obtained after the intravenous administration of $d l$-PHPB $(20 \mathrm{mg} / \mathrm{kg})$ in SD rats $(n=6,3 / \mathrm{sex})$. Each point represents the mean \pm SD. 
Table 1. The apparent first-order rate constants $(K)$ and half-lives $\left(t_{1 / 2}\right)$ of $d l$-PHPB conversion in solutions with different $\mathrm{pH}$ and SD rat plasma at $37{ }^{\circ} \mathrm{C}$. $n=3$. Values are mean \pm SEM.

\begin{tabular}{|c|c|c|c|c|c|}
\hline & & \multirow[t]{2}{*}{$K / h^{-1}$} & \multirow[t]{2}{*}{$t_{1 / 2} / \mathrm{h}$} & \multicolumn{2}{|c|}{ Received residues (\%) after the $4 \mathrm{~h}$ incubation } \\
\hline & & & & dl-PHPB & $d l$-NBP \\
\hline \multirow[t]{3}{*}{$\mathrm{pH}$} & 1.0 & $150.30 \pm 5.69$ & $4.59 \pm 0.59\left(\times 10^{-3}\right)$ & $0.00 \pm 0.00$ & $102.31 \pm 3.52$ \\
\hline & 3.0 & $1.02 \pm 0.14$ & $6.76 \pm 0.45\left(\times 10^{-1}\right)$ & $0.00 \pm 0.00$ & $99.25 \pm 5.37$ \\
\hline & 7.0 & $2.19 \pm 0.54\left(\times 10^{-3}\right)$ & $3.15 \pm 0.32\left(\times 10^{2}\right)$ & $93.03 \pm 4.71$ & $6.86 \pm 7.12$ \\
\hline
\end{tabular}

Table 2. Mean values for the pharmacokinetic parameters of active metabolite (dl-NBP) following intravenous administration of $d l$-PHPB and $d l$-NBP in Beagle dogs and SD rats $(n=6,3 /$ sex $)$.

\begin{tabular}{|c|c|c|c|c|c|c|c|c|c|}
\hline & & \multicolumn{4}{|c|}{ Beagle dogs } & \multicolumn{4}{|c|}{ SD rats } \\
\hline & & \multicolumn{3}{|c|}{ dl-PHPB } & \multirow{2}{*}{$\begin{array}{c}d l-\mathrm{NBP} \\
6.2 \mathrm{mg} / \mathrm{kg}\end{array}$} & \multicolumn{3}{|c|}{ dl-PHPB } & \multirow{2}{*}{$\begin{array}{c}\mathrm{dl} \text {-NBP } \\
15.6 \mathrm{mg} / \mathrm{kg}\end{array}$} \\
\hline & & $2 \mathrm{mg} / \mathrm{kg}$ & $4 \mathrm{mg} / \mathrm{kg}$ & $8 \mathrm{mg} / \mathrm{kg}$ & & 5 mg/kg & 10 mg/kg & $20 \mathrm{mg} / \mathrm{kg}$ & \\
\hline A & $\mu \mathrm{g} / \mathrm{mL}$ & 28.05 & 10.05 & 25.37 & 16.27 & 15.74 & 29.59 & 47.33 & 44.73 \\
\hline$\alpha$ & $\min ^{-1}$ & 1.05 & 0.22 & 0.15 & 0.11 & 0.34 & 0.16 & 0.16 & 0.20 \\
\hline B & $\mu g / m L$ & 0.80 & 4.64 & 1.02 & 3.63 & 4.47 & 1.54 & 1.47 & 1.89 \\
\hline$\beta$ & $\min ^{-1}$ & 0.07 & 0.06 & 0.02 & 0.05 & 0.06 & 0.02 & 0.02 & 0.02 \\
\hline$V_{(c)}$ & $\mathrm{L} / \mathrm{kg}$ & 0.69 & 1.36 & 0.76 & 1.05 & 0.62 & 0.80 & 1.03 & 1.05 \\
\hline$t_{(1 / 2) \alpha}$ & $\min$ & 0.66 & 3.19 & 4.75 & 6.34 & 2.04 & 4.31 & 4.33 & 3.52 \\
\hline$t_{(1 / 2) \beta}$ & $\min$ & 10.49 & 11.39 & 31.29 & 14.44 & 11.96 & 33.40 & 44.76 & 43.95 \\
\hline$K_{21}$ & $\min ^{-1}$ & 0.09 & 0.11 & 0.03 & 0.06 & 0.12 & 0.03 & 0.02 & 0.02 \\
\hline$K_{10}$ & $\min ^{-1}$ & 0.75 & 0.12 & 0.12 & 0.09 & 0.16 & 0.12 & 0.13 & 0.13 \\
\hline$K_{12}$ & $\min ^{-1}$ & 0.28 & 0.05 & 0.02 & 0.01 & 0.11 & 0.03 & 0.03 & 0.06 \\
\hline AUC & $\mu \mathrm{g} \cdot \mathrm{min} \cdot \mathrm{mL}^{-1}$ & 38.67 & 122.50 & 219.59 & 224.41 & 123.48 & 258.28 & 390.79 & 347.30 \\
\hline $\mathrm{CL}$ & $\mathrm{L} \cdot \mathrm{kg}^{-1} \cdot \mathrm{min}^{-1}$ & 0.52 & 0.17 & 0.09 & 0.08 & 0.10 & 0.10 & 0.13 & 0.15 \\
\hline
\end{tabular}

$d l$-PHPB. For this kinetic model, $t_{1 / 2} \alpha$ and $t_{1 / 2} \beta$ were 4.33 and $44.76 \mathrm{~min}$, respectively.

\section{Conversion of $d$-PHPB was affected by esterase inhibitors}

Due to the rapid conversion of $d l$-PHPB in rat plasma, the esterases mediating $d l$-PHPB metabolism were investigated by using specific inhibitors. As shown in Figure 3, in rat plasma, a nonspecific esterase inhibitor ( $\mathrm{NaF}, 200 \mathrm{mmol} / \mathrm{L})$ and metal ion chelating agents (EDTA-Na, $10 \mathrm{mmol} / \mathrm{L}$ and EGTA, $10 \mathrm{mmol} / \mathrm{L}$ ) were highly effective inhibitors of $\mathrm{dl}$ PHPB conversion (>90\%). DTNB (arylesterase inhibitor, 1 $\mathrm{mmol} / \mathrm{L}$ ), PMSF (serine esterase inhibitor, $1 \mathrm{mmol} / \mathrm{L}$ ) and BNPP (carboxylesterase inhibitor, $1 \mathrm{mmol} / \mathrm{L}$ ) showed little or no suppression of the conversion of $d$ l-PHPB. Interestingly, PMSF did not inhibit the degradation of $d l$-PHPB but was a relatively effective inhibitor of cholinesterase ${ }^{[21]}$. Donepezil (another cholinesterase inhibitor, CHEI) and teicoplanin (paraoxonase inhibitor, PONI) showed significant inhibition in concentration-dependent manners $(P<0.05)$. These results indicated that paraoxonase was likely responsible for the lactonization of $d l$-PHPB to form its active metabolite $d l-\mathrm{NBP}$ in blood. This result was consistent with the inhibitory effects of $\mathrm{NaF}$ in rat plasma; $200 \mathrm{mmol} / \mathrm{L}$ of $\mathrm{NaF}$ was sufficient to inhibit PON activity ${ }^{[22]}$.

\section{Comparative plasma pharmacokinetics}

The comparative pharmacokinetic studies of $d l-\mathrm{PHPB}$ and $d l$-NBP were carried out at equal-molar doses. The plasma concentration-time profiles of $d l$-NBP were determined following intravenous or oral administration of $d l$-PHPB and $d l$-NBP in $\mathrm{SD}$ rats and Beagle dogs. Figures $4 \mathrm{~A}$ and $4 \mathrm{~B}$ show that the concentration time curves of $d l-\mathrm{NBP}$, whether converted from dosing $d l$-PHPB or from direct intravenous administration of $d l$-NBP, were nearly identical in dogs and in rats, implying a rapid transformation of $d l$-PHPB to $d l-\mathrm{NBP}$ in blood. The main pharmacokinetic parameters of $d l-\mathrm{NBP}$ after intravenous administration of $d l$-PHPB or $d l$-NBP are summarized in Table 2. The parameters were very similar at equal-molar doses, and the areas under the curve (AUCs) were nearly the same. However, after the oral administration of $d l$-PHPB, the peak concentrations and the AUCs of $d l$-NBP in both animal models were significantly higher than those after the oral adminis- 
A

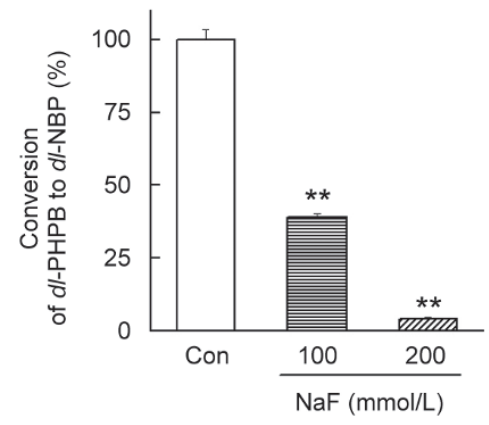

C

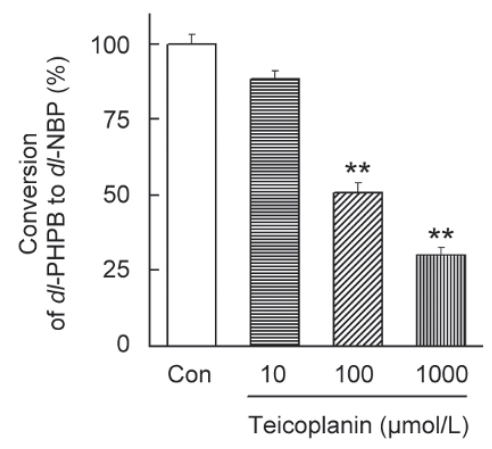

B

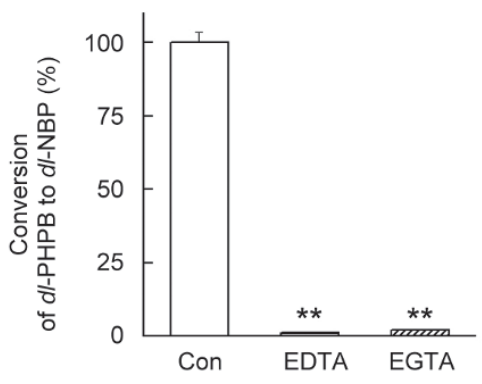

D

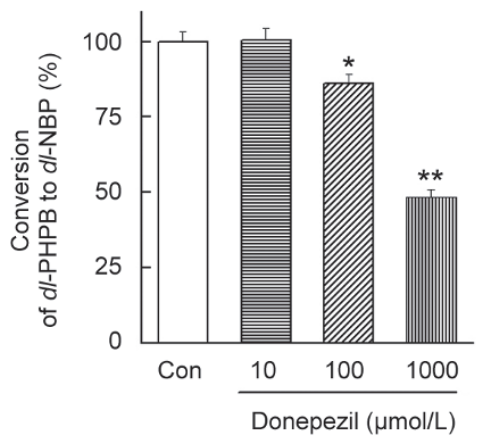

G

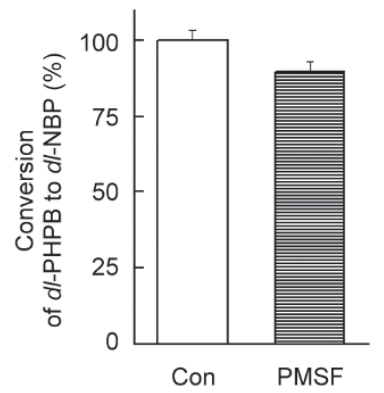

Figure 3. Effects of various esterase inhibitors on dl-PHPB conversion in rat plasma. The conversion of dl-PHPB to dl-NBP was highly effectively inhibited by $\mathrm{NaF}$ (200 mmol/L, a general esterase inhibitor) (A), and EDTA or EGTA (10 mmol/L, metal ion chelating agents) (B); partly inhibited by teicoplanin (1 mmol/L, a paraoxonase inhibitor) (C), donepezil (1 mmol/L, a cholinesterase inhibitor) (D); and negligibly inhibited by DTNB (1 mmol/L, an arylesterase inhibitor) (E), BNPP (1 mmol/L, a carboxylesterase inhibitor) (F) or PMSF ( $1 \mathrm{mmol} / \mathrm{L}$, a serine esterase inhibitor) (G) (values are the mean \pm standard error of triplicate determinations). ${ }^{*} P<0.05,{ }^{* *} P<0.01$ compared with control group.

tration of $d l$-NBP. This indicated that $d l$-PHPB was quickly absorbed and the AUC was higher than that of $d l$-NBP (Figures $4 \mathrm{C}$ and $4 \mathrm{D}$ ). The main pharmacokinetic parameters of $d l$ NBP are listed in Table 3. At equal-molar doses, ie, $30 \mathrm{mg} / \mathrm{kg}$ of $d l$-PHPB and $23.4 \mathrm{mg} / \mathrm{kg}$ of $d l-\mathrm{NBP}$ in dogs and $200 \mathrm{mg} / \mathrm{kg}$ of $d l-\mathrm{PHPB}$ and $156 \mathrm{mg} / \mathrm{kg}$ of $d l-\mathrm{NBP}$ in rats, the time to peak $\left(t_{\text {peak }}\right)$ was faster and the $C_{\max }$ and AUC were higher in the $d l-$ PHPB groups (greater by approximately two-fold or higher) than those in the $d l$-NBP groups. Other parameters did not show any significant differences.

Dose-dependent pharmacokinetics were also studied. The plasma concentration time curves of $d l$-NBP in both animal models after the intravenous or oral administration of $d l$-PHPB are shown in Figure 5, and the pharmacokinetic parameters are provided in Tables 2 and 3. The data present a linear expo- sure value in the metabolism of $d l$-NBP in beagle dogs and a dose proportional exposure value in SD rats after intravenous or oral administration of $d l$-PHPB. We also tried to detect the plasma concentration time profiles of $d l$-PHPB. However, the conversion of $d l$-PHPB in plasma was too rapid, and the concentration was too low to be detected.

\section{Distribution in tissues}

Figure 6 shows the distributions of $d l-\mathrm{NBP}$ in rat tissues after intravenous or oral treatment with $d l$-PHPB or $d l$-NBP. The levels of $\mathrm{dl}$-NBP were determined in heart, liver, lung, spleen, kidney, brain, stomach, fat, and small intestine tissues at different times after treatment. The results showed that the parent drug $d l$-NBP was primarily distributed in the stomach, kidney, fat, and brain tissues after either oral or intravenous 
Table 3. Mean values for the pharmacokinetic parameters of its active metabolite (dl-NBP) following oral administration of $d l-P H P B$ and $d l$-NBP in Beagle dogs and SD rats $(n=6,3 /$ sex).

\begin{tabular}{|c|c|c|c|c|c|c|c|c|c|}
\hline & & \multicolumn{4}{|c|}{ Beagle dogs } & \multicolumn{4}{|c|}{ SD rats } \\
\hline & & \multicolumn{3}{|c|}{ dl-PHPB } & \multirow{2}{*}{$\frac{d l-N B P}{23.4 \mathrm{mg} / \mathrm{kg}}$} & \multicolumn{3}{|c|}{ dl-PHPB } & \multirow{2}{*}{$\begin{array}{c}d l-\mathrm{NBP} \\
156 \mathrm{mg} / \mathrm{kg}\end{array}$} \\
\hline & & 10 mg/kg & 30 mg/kg & $100 \mathrm{mg} / \mathrm{kg}$ & & $50 \mathrm{mg} / \mathrm{kg}$ & 100 mg/kg & $200 \mathrm{mg} / \mathrm{kg}$ & \\
\hline$A$ & $\mu \mathrm{g} / \mathrm{mL}$ & 20.0 & 8.41 & 20.35 & 8.30 & 13.15 & 14.98 & 35.04 & 12.83 \\
\hline$K_{\mathrm{e}}$ & $\min ^{-1}$ & 0.06 & 0.01 & 0.01 & 0.01 & 0.06 & 0.04 & 0.06 & 0.02 \\
\hline$K_{a}$ & $\min ^{-1}$ & 0.09 & 0.236 & 0.09 & 0.02 & 0.30 & 0.83 & 0.67 & 0.51 \\
\hline$t_{1 / 2(\text { Ka })}$ & $\min$ & 7.89 & 2.78 & 7.37 & 33.14 & 2.31 & 1.10 & 1.10 & 1.35 \\
\hline$t_{1 / 2(\mathrm{Ke})}$ & $\min$ & 11.31 & 59.49 & 59.06 & 60.14 & 10.96 & 18.01 & 13.01 & 43.34 \\
\hline$T_{\text {(peak) }}$ & $\min$ & 13.55 & 25.29 & 13.41 & 63.47 & 6.58 & 3.60 & 4.01 & 6.96 \\
\hline$C_{(\max )}$ & $\mu \mathrm{g} / \mathrm{mL}$ & 2.64 & 6.83 & 13.23 & 1.79 & 6.84 & 14.35 & 26.04 & 11.13 \\
\hline AUC & $\mu \mathrm{g} \cdot \mathrm{min} \cdot \mathrm{mL}^{-1}$ & 98.90 & 686.0 & 1518.00 & 323.50 & 262.80 & 478.00 & 1082.70 & 777.80 \\
\hline $\mathrm{CL} / \mathrm{F}(\mathrm{s})$ & L/kg & 0.10 & 0.02 & 0.02 & 0.03 & 0.08 & 0.08 & 0.06 & 0.03 \\
\hline $\mathrm{V} / \mathrm{F}(\mathrm{c})$ & $\mathrm{L} \cdot \mathrm{kg}^{-1} \cdot \mathrm{min}^{-1}$ & 1.70 & 1.25 & 1.68 & 2.65 & 1.28 & 1.79 & 1.24 & 1.50 \\
\hline
\end{tabular}

A

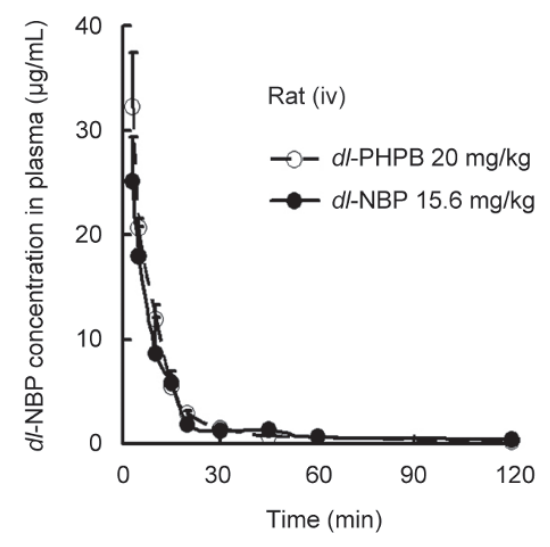

C

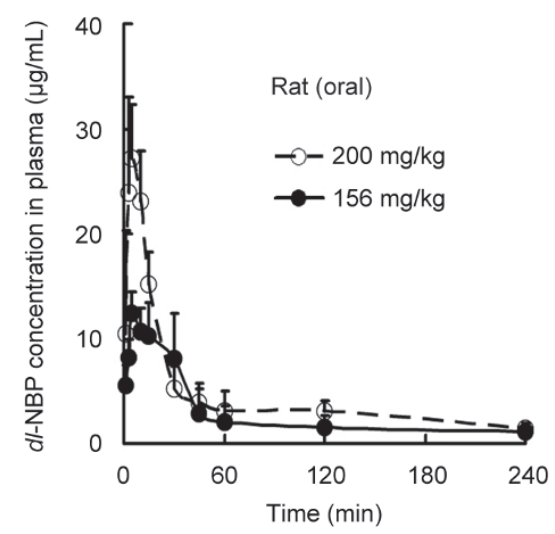

B

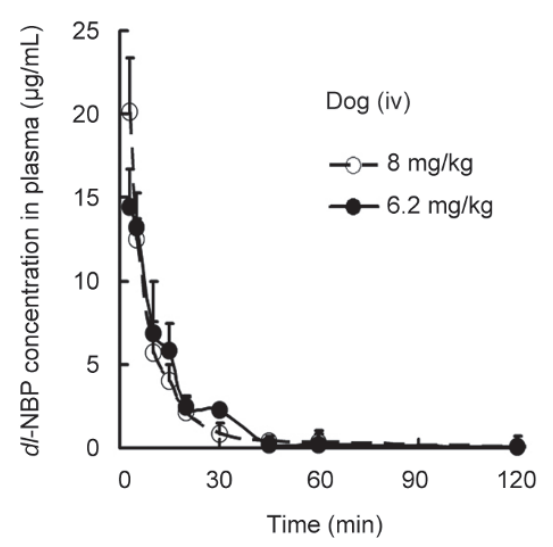

$\mathrm{D}$

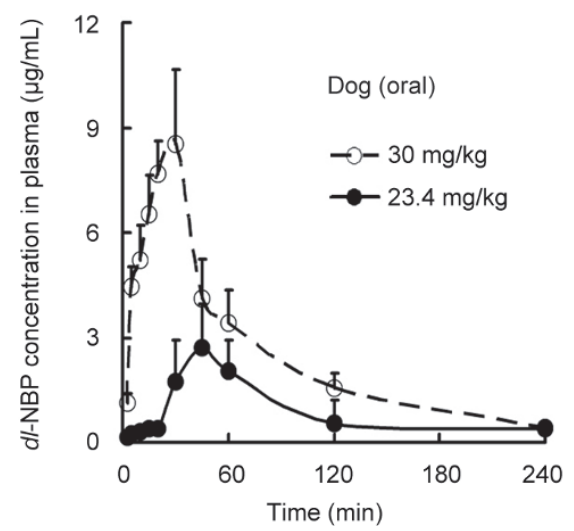

Figure 4. Comparative plasma concentration versus time profiles of $d l$-NBP after administration of $d l-\mathrm{PHPB}$ and $d l$-NBP. Based on the molecular weights of two compounds, dl-PHPB and dl-NBP were intravenously administered to SD rats (A: $20 \mathrm{mg} / \mathrm{kg}$ for $\mathrm{dl}$-PHPB, and $15.6 \mathrm{mg} / \mathrm{kg}$ for $\mathrm{dl}-\mathrm{NBP}$ ) or Beagle dogs (B: $8 \mathrm{mg} / \mathrm{kg}$ for dl-PHPB, and $6.2 \mathrm{mg} / \mathrm{kg}$ for dl-NBP); and orally administered in SD rats (C: $200 \mathrm{mg} / \mathrm{kg}$ for $\mathrm{dl}$-PHPB, and $156 \mathrm{mg} / \mathrm{kg}$ for dlNBP) and Beagle dogs (D: $30 \mathrm{mg} / \mathrm{kg}$ for dl-PHPB, and $23.4 \mathrm{mg} / \mathrm{kg}$ for dl-NBP). Blood samples were obtained at 0, 1, 3, 5, 10, 15, 20, 30, 45, 60, 120, and $240 \mathrm{~min}$ after administration. Values are mean \pm standard deviation $(n=6,3 / \mathrm{sex})$. 
treatment with $d l$-PHPB or $d l$-NBP. The highest concentrations of $d l$-NBP appeared in the stomach and in fat after oral or intravenous treatment. In brain distribution, relatively higher levels were observed at different times after $d l$-PHPB treatment than after $d l$-NBP treatment, especially with oral administration; maximum concentrations of $40.6 \pm 8.9 \mathrm{\mu g} / \mathrm{g}$ at $60 \mathrm{~min}$ and $25.4 \pm 11.9 \mathrm{\mu g} / \mathrm{g}$ were observed, respectively.

Table 4. Cumulative recovery of $d l$-NBP (percentage of dose) in urine or feces within $72 \mathrm{~h}$, after equimolar oral administration of dl-PHPB or dlNBP in rats $(n=6,3 /$ sex, values are mean \pm SEM).

\begin{tabular}{lcccc}
\hline $\begin{array}{l}\text { Time } \\
\text { interval }\end{array}$ & \multicolumn{2}{c}{ dl-PHPB (100 mg/kg) } & \multicolumn{2}{c}{ dl-NBP (78 mg/kg) } \\
& Feces (\%) & Urine (\%) & Feces (\%) & Urine (\%) \\
\hline $4 \mathrm{~h}$ & $0.32 \pm 0.03$ & $0.07 \pm 0.02$ & $0.21 \pm 0.01$ & $0.02 \pm 0.00$ \\
$8 \mathrm{~h}$ & $0.90 \pm 0.40$ & $0.12 \pm 0.04$ & $0.48 \pm 0.01$ & $0.03 \pm 0.00$ \\
$12 \mathrm{~h}$ & $1.77 \pm 0.56$ & $0.20 \pm 0.05$ & $0.82 \pm 0.01$ & $0.18 \pm 0.11$ \\
$24 \mathrm{~h}$ & $2.17 \pm 0.72$ & $0.36 \pm 0.10$ & $1.13 \pm 0.04$ & $0.23 \pm 0.11$ \\
$48 \mathrm{~h}$ & $2.43 \pm 0.70$ & $0.46 \pm 0.12$ & $1.16 \pm 0.04$ & $0.25 \pm 0.11$ \\
$72 \mathrm{~h}$ & $2.44 \pm 0.69$ & $0.47 \pm 0.12$ & $1.40 \pm 0.04$ & $0.25 \pm 0.10$ \\
\hline
\end{tabular}

A

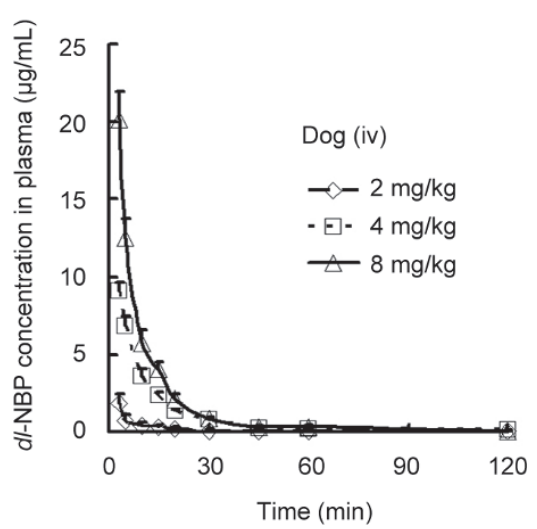

C

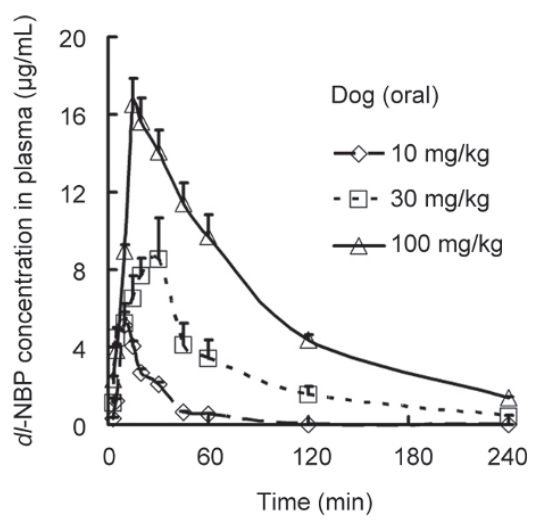

\section{Excretion of $d I-\mathrm{PHPB}$}

After equal-molar doses of $d l$-PHPB or $d l$-NBP by oral or intravenous administration, the cumulative recovery of $d l$ NBP in urine and feces of SD rats is shown in Tables 4 and 5. Less than $5 \%$ of $d l$-NBP was recovered in urine and feces after oral treatment of either compound within $72 \mathrm{~h}$. Dl-PHPB was

Table 5. Cumulative recovery of $d I$-NBP (percentage of dose) in urine within $48 \mathrm{~h}$, after intravenous equimolar administration of $d l-P H P B$ or $d l-$ NBP in rats $(n=6,3 /$ sex, values are mean \pm SEM).

\begin{tabular}{lcc}
\hline $\begin{array}{l}\text { Time } \\
\text { intervals }\end{array}$ & $\begin{array}{c}\text { dl-PHPB }(10 \mathrm{mg} / \mathrm{kg}) \\
\text { Urine (\%) }\end{array}$ & $\begin{array}{c}\text { dl-NBP }(7.8 \mathrm{mg} / \mathrm{kg}) \\
\text { Urine }(\%)\end{array}$ \\
\hline $4 \mathrm{~h}$ & $2.38 \pm 0.37$ & $1.46 \pm 0.93$ \\
$8 \mathrm{~h}$ & $2.87 \pm 0.43$ & $2.19 \pm 0.88$ \\
$12 \mathrm{~h}$ & $3.12 \pm 0.43$ & $2.51 \pm 0.89$ \\
$24 \mathrm{~h}$ & $3.41 \pm 0.43$ & $2.58 \pm 0.87$ \\
$36 \mathrm{~h}$ & $3.58 \pm 0.44$ & $2.73 \pm 0.86$ \\
$48 \mathrm{~h}$ & $3.75 \pm 0.41$ & $2.94 \pm 0.85$ \\
\hline
\end{tabular}

dl-NBP was undetectable in feces.

B

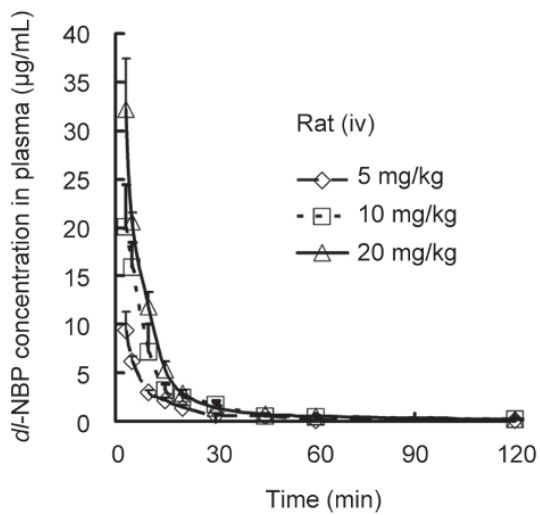

D

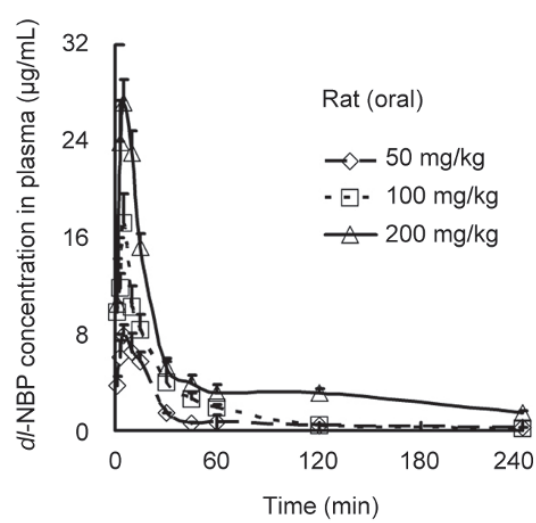

Figure 5. Mean plasma concentration versus time profiles of $d l$-NBP after the administration of $d l$-PHPB. DI-PHPB was intravenously administered in Beagle dogs (A: 2, 4, and $8 \mathrm{mg} / \mathrm{kg}$ ) and SD rats (B: 5, 10, and $20 \mathrm{mg} / \mathrm{kg}$ ); and orally administered in Beagle dogs (C: 10, 30, and 100 mg/kg) and SD rats (D: 50, 100, and $200 \mathrm{mg} / \mathrm{kg}$ ). Blood samples were obtained at 0, 1, 3, 5, 10, 15, 20, 30, 45, 60, 120, and 240 min after administration. Values are the mean \pm standard deviation $(n=6,3 / \mathrm{sex})$. 
A

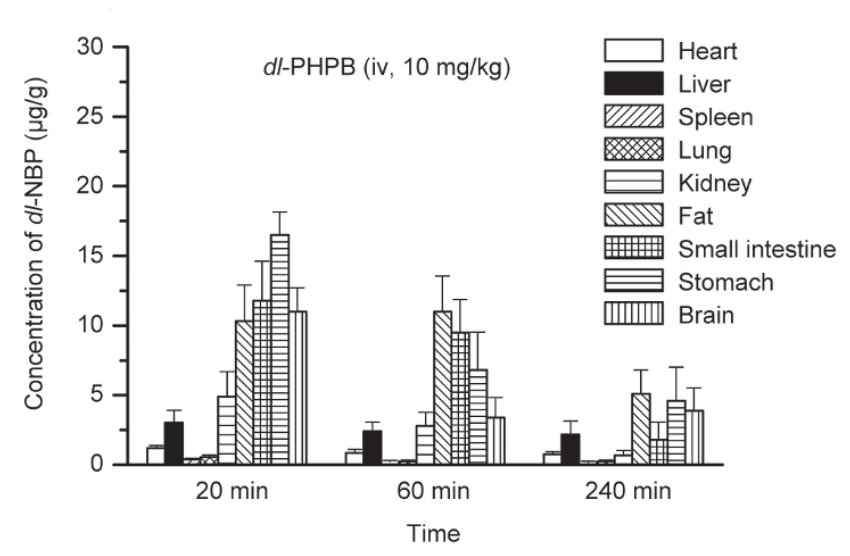

C

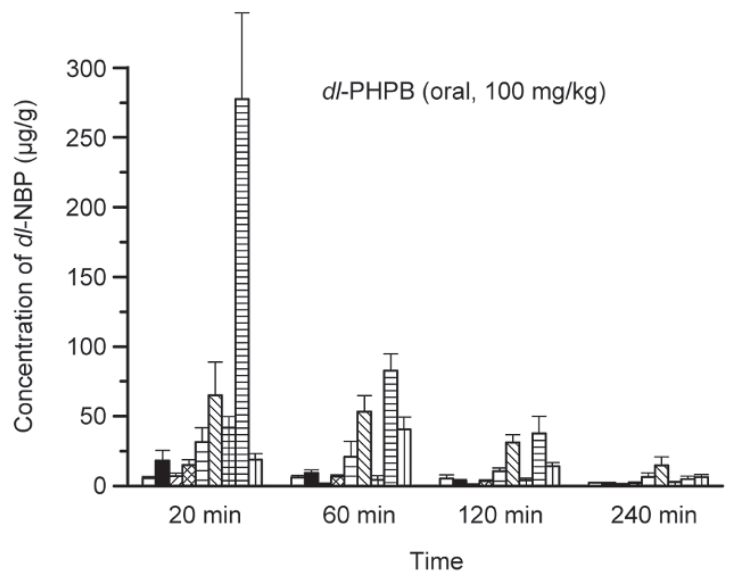

B

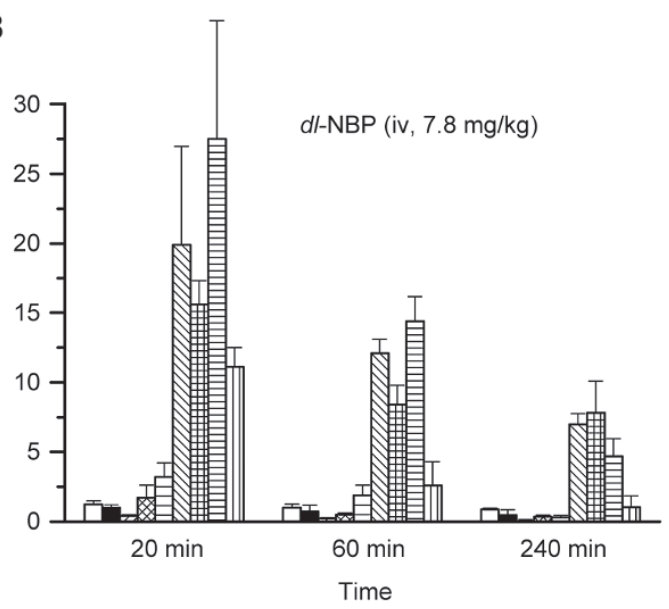

D

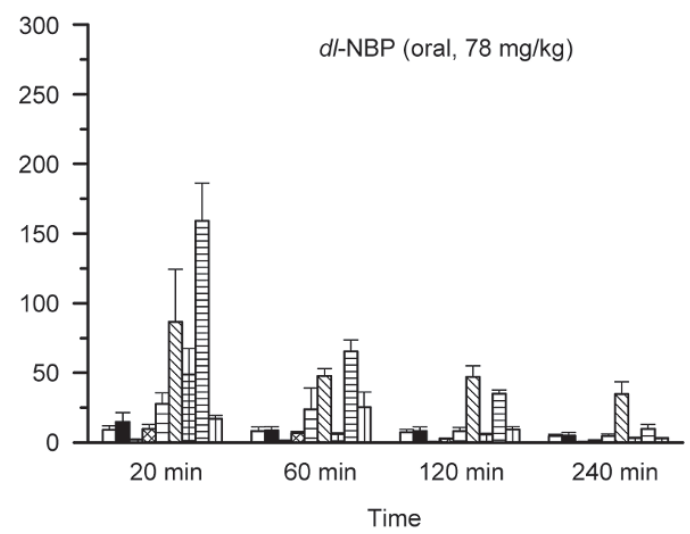

Figure 6. Tissue distribution of dl-NBP after equimolar dosing of $d l-\mathrm{PHPB}$ and $d \mathrm{l}$-NBP in SD rats. The tissues were obtained at 20,60 , and 240 min after dl-PHPB (A: $10 \mathrm{mg} / \mathrm{kg}$ ) or dl-NBP (B: $7.8 \mathrm{mg} / \mathrm{kg}$ ) injection or at 20,60, 120, and $240 \mathrm{~min}$ after oral dl-PHPB (C: $100 \mathrm{mg} / \mathrm{kg}$ ) or dl-NBP (D: 78 $\mathrm{mg} / \mathrm{kg})$ administration. Values are the mean \pm standard deviation $(n=6,3 / \mathrm{sex})$.

undetectable in the urine and feces of the $d l$-PHPB group. The excretion rates of $d l$-NBP in the urine or feces were similar between the two compounds, by either oral or intravenous administration, which implied that $d l$-PHPB was converted to $d l-\mathrm{NBP}$ and was then excreted as metabolites.

\section{Discussion}

The elucidation of the conversion mechanism of pro-drugs in chemical and biological samples is essential for enhancing pharmacological efficacy and safety. $\mathrm{Dl}$-PHPB is liable to lactonization of the hydroxyl acid to form the pharmacologically active metabolite $d l$-NBP. The oral AUC value of the converted $d l$-NBP from $d l$-PHPB was two- to three-fold greater than that of $d l$-NBP directly administered.

Esters are typically unstable compounds in vivo due to esterases in bio-matrices ${ }^{[23]}$. Studies have identified in vitro hydrolyzing ester compounds in bio-samples that are involved in the in vivo metabolic pathway ${ }^{[24-28]}$. Non-enzymatic conversions indicate that chemical lactonization can occur. This $\mathrm{pH}-$ dependent conversion is important due to the various $\mathrm{pH}$ conditions encountered in the stomach ( $\mathrm{pH} 2.0)$, bile $(\mathrm{pH} 8.5)$, plasma ( $\mathrm{pH} 7.4$ ) and intestines ( $\mathrm{pH}$ 6.8). Because dl-PHPB is quite stable in alkaline conditions, $d l$-PHPB could be stored (could not be converted) in alkaline aqueous solutions.

The conversion rate was more rapid in rat plasma samples than in non-enzymatic solutions, indicating that enzymatic lactonization is the key mode of conversion in plasma. The conversion was markedly inhibited in rat plasma by $\mathrm{NaF}, \mathrm{a}$ general esterase inhibitor ${ }^{[14,22,29]}$, confirming that one or several plasma esterases are involved in $d l$-PHPB metabolism. Moreover, the conversion in rat plasma was almost completely inhibited by EDTA and EGTA (a general chelating agent for calcium) at $10 \mathrm{mmol} / \mathrm{L}$ and significantly restrained by donepezil (AChE inhibitor) ${ }^{[30]}$ and teicoplanin (PON inhibitor) in a concentration-dependent manner ${ }^{[31]}$. However, PMSF, another inhibitor of $\mathrm{AChE}^{[21]}$, did not show any inhibitory effects on $\mathrm{dl}$ PHPB transformation. Additionally, due to the presence of calcium-dependent lactonase in sera ${ }^{[23,32]}$. EDTA and EGTA are potent inhibitors of PON and arylesterase via calcium ion chelation, which is essential for their hydrolytic activity ${ }^{[3,34]}$. Thus, 
the results suggested that $\mathrm{PON}$ may be primarily responsible for the conversion of $d l$-PHPB in the plasma esterase.

The HPLC analyses of plasma samples after intravenous or oral treatment indicated a rapid and complete conversion of $d l$-PHPB to its active form ( $d l$-NBP) in blood, which was consistent with the conversion in vitro studies (in non-enzymatic acidic solution or rat plasma). As described above, the conversion of $d l$-PHPB in plasma was too fast to be detected. After intravenous or oral dosing, the concentrations of $d l$-PHPB in plasma rapidly declined within $30 \mathrm{~min}$, whereas $d l$-NBP concentrations remained at higher levels until $240 \mathrm{~min}$. Thus, the metabolism of $d l$-PHPB, such as plasma pharmacokinetics, tissue distribution, and excretion, were carried out on its active form ( $d l$-NBP) of $d l$-PHPB in SD rats and Beagle dogs. Compared with the oral administration of equal-molar doses of $d l$ NBP, the total drug exposure expressed as AUC and the $C_{\max }$ of the converted $d l$-NBP were two-fold higher in SD rats and Beagle dogs after the oral administration of $d l$-PHPB. We also found that the pharmacokinetic parameters of $d l$-NBP following intravenous administration of $d l$-PHPB in rats and dogs were similar to those of $d l$-NBP based on equal-molar dosages. Thus, the pharmacokinetic profile of $d l$-PHPB showed a rapid absorption, and the converted $d l$-NBP showed a higher bioavailability.

The distribution study showed that the concentrations of $d l$ NBP were low or undetected in all tissues after $240 \mathrm{~min}$, indicating no long-term accumulation after oral dl-PHPB administration. However, there was a relatively higher distribution in fat tissue than in $d l$-NBP-treated animals after intravenous dosing of $d l$-PHPB. These effects may help to maintain plasma drug concentrations and may result in higher bioavailability. When $d l$-PHPB was orally administered, the distribution of converted $d l$-NBP in rat brain was enhanced by $60 \%$ compared with that observed in oral equal-molar doses of $d l$-NBP. The high distribution in the brain confirmed the pharmacological effects of $d l$-NBP on anti-cerebral ischemia ${ }^{[1,5-7]}$ and the therapeutic benefit of $d l$-PHPB.

Our study showed that no original form of $d l$-PHPB was excreted and only less than $5 \%$ of $d l$-NBP was recovered in the urine and feces after the administration of $d l$-PHPB in SD rats within $72 \mathrm{~h}$. Because of the rapid and complete conversion of $d l$ $\mathrm{PHPB}$ to $d l-\mathrm{NBP}$, this may indicate that the converted $d l$-PHPB to $d l$-NBP in blood or tissues was primarily excreted in the parent-drug form. A low percentage of the parent-drug form was detected in urine and feces. Similar observations have been reported in rats after the administration of $d l-\mathrm{NBP}^{[35,36]}$. Within $24 \mathrm{~h}$ following oral $\left[{ }^{3} \mathrm{H}\right]-\mathrm{NBP}$ administration, the total radioactivity in urine and feces was $73.1 \%$ of the original dose, and the total prototype drug excreted in urine and feces was $2.53 \%$ of the dose $^{[36]}$. Furthermore, 23 metabolites of $d l$-NBP were detected in human plasma and urine ${ }^{[37]}$. Thus, the metabolic pathway of $d l$-PHPB in vivo may be similar to that of $d l$-NBP. Additionally, dl-PHPB is a weakly basic drug, exhibits pH-dependent stabilization and is susceptible to gastric and intestinal (GI) tract $\mathrm{pH}$ change. The varying GI $\mathrm{pH}$ levels may also contribute to differences in drug absorption. The rate of gastric acid secretion is known to be widely different among species. For example, rats and humans have good acid secretions but dogs have poor secretions ${ }^{[38-41]}$. In the present study, the results showed that the bioavailability of $d l$-PHPB in dogs was higher than that in rats. The differences in bioavailability between dogs and rats are most likely due to low basal gastric acid secretions increasing GI $\mathrm{pH}$ and enhancing the stabilization of $d l$-PHPB in this species. Further studies are required to clarify the effects of $\mathrm{pH}$ changes on the metabolism of $d l$-PHPB, conversion mechanisms, metabolic pathways for $d l$-PHPB, and potential interactions with other drugs.

In conclusion, as a pro-drug, $d l$-PHPB was rapidly and completely converted into $d l-\mathrm{NBP}$ after treatment in rats and dogs. The $C_{\max }$ and AUC values of $d l$-NBP converted from $d l$ $\mathrm{PHPB}$ were significantly higher than those from direct $d l$-NBP administration. Conversion in vivo was primarily mediated by plasma esterases. The active form was more distributed in fat and brain tissues. The dl-PHPB metabolic pathway after conversion may follow that of $d l$-NBP.

\section{Acknowledgements}

This study was supported by grants from the National Science and Technology Major Special Project on Major New Drug Innovation of China (№ 2012ZX09301002-004) and the Beijing Key Laboratory of New Drug Mechanisms and Pharmacological Evaluation Study (№ BZ0150).

\section{Author contribution}

Xiao-liang WANG conceived and designed the experiments; Jiang LI, Shao-feng XU, Nan FENG, and Ling WANG performed the experiments; Jiang LI wrote the paper; Xiao-liang WANG, Jiang LI, and Ying PENG analyzed the data.

\section{References}

1 Zhang Y, Wang L, Li J, Wang XL. 2-(1-Hydroxypentyl)-benzoate increases cerebral blood flow and reduces infarct volume in rats model of transient focal cerebral ischemia. J Pharmacol Exp Ther 2006; 317: 973-9.

2 XU Z, HU GY, TAN GS. Comparative research on methods of n-butylphthalide synthesis. China J Modern Med 2004; 14: 91-3.

3 Wang XW. 3-n-Butylphthalide. Drugs Future 2000; 25: 16-23.

4 Dong GX, Feng YP. Effects of NBP on ATPase and anti-oxidant enzymes activities and lipid peroxidation in transient focal cerebral ischemic rats. Acta Acad Med Sin 2002; 24: 93-7.

5 Cui LY, Liu XQ, Zhu YC, Fan DS, Xie RP, Shen Y, et al. Effects of dl-3butylphthalide on treatment of acute ischemic stroke with moderate symptoms: a multi-center, randomized, double-bind, placebo-control trial. Chin J Neurol 2005; 38: 251-4.

6 Cerebrovascular Disease Working Groups, Chinese Academy of Neurology. Guidelines for the management of iscemic stroke (China 2010). Chin J Neurol 2010; 43: 146-53.

$7 \mathrm{Xu} \mathrm{B}$, Zhao ZG. Butylphthalide injection, an innovative drug originated in China for the treatment of ischemic stroke. Chin J New Drugs 2011; 20: $947-50$.

8 Zhang Y, Wang L, Zhang LY, Wang XL. Effects of 2-(1-hydroxypentyl)benzoate on platelet aggregation and thrombus formation in rats. Drug Dev Res 2004; 63: 174-80. 
9 Yang HY, Xu SF, Li J, Wang L, Wang XL. Potassium 2-(1-hydroxypentyl)benzoate inhibits ADP-induced rat platelet aggregation through P2Y1PLC signaling pathways. Naunyn Schmiedebergs Arch Pharmacol 2015; 388: 983-90.

10 Zhao WH, Xu SF, Peng Y, Ji XC, Cao DX, Li J, et al. Potassium 2-(1-hydroxypentyl)-benzoate improves learning and memory deficits in chronic cerebral hypoperfused rats. Neurosci Lett 2013; 541: 15560.

11 Li PP, Wang WP, Liu ZH, Xu SF, Lu WW, Wang L, et al. Potassium 2-(1-hydroxypentyl)-benzoate promotes long-term potentiation in $A \beta_{1-42}$-injected rats and APP/PS1 transgenic mice. Acta Pharmacol Sin 2014; 35: 869-78.

12 Peng Y, Hu YL, Xu SF, Rong XF, Li J, Li PP, et al. Potassium 2-(1-hydroxypentyl)-benzoate improves memory deficits and attenuates amyloid and $\mathrm{T}$ pathologies in a mouse model of Alzheimer's disease. J Pharmacol Exp Ther 2014; 350: 361-74.

$13 \mathrm{Hu}$ YL, Peng Y, Long Y, Xu SF, Feng N, Wang L, et al. Potassium 2-(1-hydroxypentyl)-benzoate attenuated hydrogen peroxide-induced apoptosis in neuroblastoma SK-N-SH cells. Eur J Pharmacol 2012; 680: 49-54.

14 Tsujikawa K, Kuwayama K, Miyaguchi H, Kanamori T, Iwata YT, Inoue $\mathrm{H}$. In vitro stability and metabolism of salvinorin $\mathrm{A}$ in rat plasma. Xenobiotica 2009; 39: 391-8.

15 Koitka M, Höchel J, Gieschen H, Borchert HH. Improving the ex vivo stability of drug ester compounds in rat and dog serum: Inhibition of the specific esterases and implications on their identity. J Pharm Biomed 2010; 51: 664-78.

16 Gil F, Gonzalvo MC, Hernandez AF, Villanueva E, Pla A. Differences in the kinetic properties, effect of calcium and sensitivity to inhibitors of paraoxon hydrolase activity in rat plasma and microsomal fraction from rat liver. Biochem Pharmacol 1994; 48: 1559-68.

17 Sogorb MA, Sánchez I, López-Rivadulla M, Céspedes V, Vilanova E. EDTA-resistant and sensitive phosphotriesterase activities associated with albumin and lipoproteins in rabbit serum. Drug Metab Dispos 1999; 1: 53-9.

18 Li J, Wang XL, Wang AP, Xu SF, Jin HT. Toxicokinetics and toxicity of potassium 2-(1-hydroxypentyl)-benzoate in beagle dogs. J Asian Nat Prod Res 2017; 19: 388-401.

19 Li J, Wang AP, Wang XL, Xu SF, Li J, Li H, et al. Experimental study on repeated dose toxicity and toxicokinetics of dl-PHPB by intravenous injection in Beagle dogs. Modern Med J China 2011; 13: 1-3.

20 Li J, Wang AP, Wang XL, Xu SF, Li J, Li H, et al. Experimental study on repeated dose toxicity and toxicokinetics of $d /$-PHPB by intravenous injection in Beagle dogs. Modern Med J China 2011; 13: 1-3.

21 Turini P, Kurooka S, Steer M, Corbascio AN, Singer TP. The action of phenylmethylsulfonyl fluoride on human acetylcholinesterase, chymotyrpsin and trypsin. J Pharmacol Exp Ther 1969; 167: 98-104.

22 Dean RA, Christian CD, Sample RHB, Bosron WF. Human liver cocaine esterases: ethanol-mediated formation of ethylcocaine. FASEB J 1991; 5: 2735-9.

23 Liederer BM, Borchardt RT. Enzymes involved in the bioconversion of ester-based prodrugs. J Pharm Sci 2006; 95: 1177-95.
24 Williams FM, Moore U, Seymour RA, Mutch EM, Nicholson E, Wright P, et al. Benorylate hydrolysis by human plasma and human liver. $\mathrm{Br} J$ Clin Pharmacol 1989; 28: 703-8.

25 Li W, Escarpe PA, Eisenberg EJ, Cundy KC, Sweet C, Jakema KJ, et al. Identification of GS 4104 as an orally bioavailable prodrug of the influenza virus neuraminidase inhibitor GS 4071. Antimicrob Agents Ch 1998; 42: 647-53.

26 Prueksaritanont T, DeLuna P, Gorham LM, Ma B, Cohn D, Pang J, et al. In vitro and in vivo evaluations of intestinal barriers for the zwitterion L-767,679 and its carboxyl ester prodrug L-775,318. Roles of efflux and metabolism. Drug Metab Dispos 1998; 26: 520-7.

27 Ericsson $\mathrm{H}$, Tholander B, Regårdh CG. In vitro hydrolysis rate and protein binding of clevidipine, a new ultrashort-acting calcium antagonist metabolised by esterases, in different animal species and man. Eur J Pharm Sci 1999; 8: 29-37.

28 Anand SS, Bruckner JV, Haines WT, Muralidhara S, Fisher JW, Padilla S. Characterization of deltamethrin metabolism by rat plasma and liver microsomes. Toxicol Appl Pharm 2006; 212: 156-66.

29 Wei RD, Chu FS. Modification of in vitro metabolism of T-2 toxin by esterase inhibitors. Appl Environ Microb 1985; 50: 115-9.

30 Bryson HM, Benfield P. Donepezil. Drugs Aging 1997; 10: 234-49, discussion 240-1.

31 Ekinci D, Beydemir S. Evaluation of the impacts of antibiotic drugs on PON 1; a major bioscavenger against cardiovascular diseases. Eur J Pharmacol 2009; 617: 84-9.

32 Roth RH, Levy R, Giarman NJ. Dependence of rat serum lactonase upon calcium. Biochem Pharmacol 1967; 16: 596-8.

33 Gonzalvo MC, Gil F, Hernández AF, Villanueva E, Pla A. Inhibition of paraoxonase activity in human liver microsomes by exposure to EDTA, metals and mercurials. Chem-Biol Interact 1997; 105: 169-79.

34 Kuo CL, La Du BN. Calcium binding by human and rabbit serum paraoxonases. Structural stability and enzymatic activity. Drug Metab Dispos 1998; 26: 653-60.

35 Peng SH, Zhou TH. Investigation on in vivo metabolism of 3-n-butylphthalide. Acta Pharm Sin 1996; 31: 780-4.

36 Wang $\mathrm{CH}$, Feng YP, Wu YL. A study on the metabolites of $\mathrm{dl}-3-\mathrm{N}$ butyphthalide in rats. Acta Pharm Sin 1997; 32: 641-6.

37 Diao XX, Deng P, Xie C, Li XL, Zhong DF, Zhang YF. Metabolism and pharmacokinetics of 3-n-butylphthalide (NBP) in humans: the role of cytochrome P450s and alcohol dehydrogenase in biotransformation. Drug Metab Dispos 2013; 41: 430-44.

38 Pappas TN, Debas HT, Goto Y, Taylor IL. Peptide YY inhibits mealstimulated pancreatic and gastric section. Am J Physiol 1985; 248 : G118-23.

39 Emås S, Grossman MI. Response of Heidenhain pouch to histamine, gastrin and feeding before and after truncal vagotomy in dogs. Scand J Gastroenterol 1969; 4: 497-503.

40 Petersen H, Grossman MI. Stimulation of gastric acid secretion by dimaprit in unanesthetized rats. Agents Actions 1978; 8: 566-7.

41 Wormsley KG, Grossman ME. Maximal histalog test in control subjects and patients with peptic ulcer. Gut 1965; 6: 427-35. 